\title{
Effects of Self-Other Decision Making on Regulatory Focus and Choice Overload
}

\author{
Evan Polman \\ New York University
}

\begin{abstract}
A growing stream of research is investigating how choices people make for themselves are different from choices people make for others. In this paper, I propose that these choices vary according to regulatory focus, such that people who make choices for themselves are prevention focused, whereas people who make choices for others are promotion focused. Drawing on regulatory focus theory, in particular work on errors of omission and commission, I hypothesize that people who make choices for others experience a reversal of the choice overload effect. In 6 studies, including a field study, I found that people who make choices for themselves are less satisfied after selecting among many options compared to few options, yet, people who make choices for others are more satisfied after selecting among many options compared to few options. Implications and suggestions for other differences in self-other decision making are discussed.
\end{abstract}

Keywords: self-other decision making, regulatory focus, choice overload

People are hired, even elected, to make choices on behalf of others-consultants, politicians, and board members are three examples. And the quality and success of their choices depend on the amount and type of information that is considered during the decision process (Payne, 1976). We might think at first glance that people who make choices on behalf of others are less enmeshed in choices and therefore more objective in assimilating and construing information. Put differently, people who make choices for others may suffer fewer cognitive biases. A lawyer, for example in a divorce proceeding, may see the opposition's argument more clearly than a client; or a real estate agent may more accurately generate a selling price than an owner. It is possible, however, that the net effect of deciding for others is accompanied with greater, not fewer systematic biases, and that the two examples provided here represent exceptions to this rule.

Indeed, a small but growing research stream has documented cognitive biases among decision makers who specifically choose on behalf of others and reported that omission bias, confirmation bias, lexicographic weighting, and predecisional distortion of information are greater among decision makers who decide on

This article was published Online First March 19, 2012.

An earlier version of this paper received the 2009 Hillel Einhorn New Investigator Award from the Society for Judgment and Decision Making for best paper by a new researcher and was nominated for the 2010 William H. Newman Award by the Academy of Management for best paper based on a recent dissertation. I especially thank my dissertation chair, Jack Goncalo, for his generosity and guidance, and the rest of my committee, Jay Russo, Michele Williams, and Brian Wansink, for their helpful feedback. I am also grateful to Verlin Hinsz for constructive and valuable suggestions.

Correspondence cornering this article should be addressed to Evan Polman, 701C Tisch Hall, Stern School of Business, New York University, 40 West 4th Street, New York, NY 10012. E-mail: epolman@ stern.nyu.edu others' behalves in relation to their own behalves (Jonas, SchulzHardt, \& Frey, 2005; Kray, 2000; Polman, 2010; Zikmund-Fisher, Sarr, Fagerlin, \& Ubel, 2006). Risk preferences have also been found to differ among decision makers, with some research reporting that decisions tend to be more risky when made on behalf of others (Beisswanger, Stone, Hupp, \& Allgaier, 2003; Stone, Yates, \& Caruthers, 2002; Wray \& Stone, 2005) and other research reporting that decisions tend to be less risky when made on behalf of others (McCauley, Kogan, \& Teger, 1971; Teger \& Kogan, 1975; Wallach, Kogan, \& Bem, 1964; Zaleska \& Kogan, 1971). Although it is evident that decision making is different when people decide for others compared to when people decide for the self, it is not fully understood why these differences occur. The current research builds on this general theme by exploring whether self-other differences in decision making can be explained by regulatory focus theory (Higgins, 1987, 1997).

Research has shown that people who make choices for others (i.e., proxy decision makers) examine and seek out more information than people who make their own choices (i.e., personal decision makers; Jonas et al., 2005; Kray, 2000; Polman, 2010; Polman \& Emich, 2011). In a study by Jonas and Frey (2003), decision makers who were instructed to play the role of a travel agent and recommend a trip, sought out more travel information than decision makers who were instructed to make travel choices for themselves. However, research does not show if the choice attributes themselves are differentially attended. If proxy decision makers typically take into consideration more information than personal decision makers, then it is possible for proxy decision makers to focus on choice attributes that are qualitatively different from those focused on by personal decision makers. Indeed, Beisswanger et al. (2003) found in a study on risk taking in relationships, that individuals encourage their friends to take risks that they themselves would not take, such as going out on a blind date. Of import, proxy decision makers gave more positive reasons compared to personal decision makers, and vice versa, personal 
decision makers gave more negative reasons compared to proxy decision makers.

Although current research has not yet linked regulatory focus theory with self-other differences in decision making, Beisswanger et al.'s results appear to be consistent with the behaviors one would expect from individuals who are in a particular regulatory focus. That is, regulatory focus theory identifies two basic motivational orientations that individuals adopt in the process of making a choice. Individuals in a promotion focus are sensitive to the presence and absence of positive outcomes, whereas individuals in a prevention focus are sensitive to the presence and absence of negative outcomes (Crowe \& Higgins, 1997; Higgins, 2000; Higgins, Shah, \& Friedman, 1997; Lockwood, Jordan, \& Kunda, 2002). Consider another example from Beisswanger et al. (2003) to see how regulatory focus may be associated with self-other decision making: "Your best friend asks you whether she should go on a blind date this weekend, and you immediately respond 'absolutely.' Would you, however, respond so quickly and affirmatively if you were the one potentially going on the blind date?" (p. 121). Incorporating regulatory focus with self-other decision making, I suggest that in a choice for the self, the answer to the preceding question is probably "no" because negative outcomes such as a boring date or an unattractive partner can be anticipated (and doubt and fear may be experienced); whereas in a choice for somebody else, the answer is probably "yes" because positive outcomes like making a new friend or a potential mate can be anticipated (and excitement may be experienced).

In this paper I hypothesize that a choice on behalf of the self elicits relatively more prevention focus, and conversely, that a choice on behalf of another elicits relatively more promotion focus. Moreover, this paper seeks to investigate whether differences in regulatory focus occur among personal and proxy decision makers juxtaposed to a context in which decision makers choose among either many options or few options. On account of the possibility that some of the decision heuristics and biases are enhanced, reduced, nonexistent, or even reversed when choices are made on behalf of others, I explore how one particular phenomenon, choice overload (i.e., experiencing more satisfaction after choosing among few options compared to many options; cf. Iyengar \& Lepper, 2000; Scheibehenne, Greifeneder, \& Todd, 2010), operates in choices that are made on behalf of others. Thus, this paper addresses two research questions: Does a different regulatory focus trigger among decision makers who decide on others' behalves compared to their own behalves? And does experiencing a different regulatory focus cause decision makers to be more, or less satisfied, after choosing among many options?

Besides being interesting questions in their own rightregulatory focus is considered one of the most influential theories in psychology, generating considerable research into the formation of values, beliefs, attitudes, motivations, emotions, and behaviors-I was drawn to this issue because the number of options that decision makers choose among has been found to contribute to contradictory levels of satisfaction. On one hand, choosing among many options is considered a fundamental axiom in economics to enhance well-being, and in fact, has been shown to increase positive outcomes such as purchase behavior, consumption, and satisfaction (Anderson, Taylor, \& Holloway, 1966; Kahn \& Wansink, 2004; Koelemeijer \& Oppewal, 1999). Likewise, having many options reduces the cost of searching for more options, makes it easier to get a sense of the overall quality among options, and increases decision makers' freedom of choice (Eaton \& Lipsey, 1979; Hutchinson, 2005; Reibstein, Youngblood, \& Fromkin, 1975). On the other hand, research in psychology has found that choosing among many options leads to negative affective responses such as regret, pessimism, demotivation, and ultimately choice withdrawal (e.g., Iyengar \& Jiang, 2004; Iyengar \& Lepper, 2000; Iyengar, Wells, \& Schwartz, 2006; Schwartz, 2004). In their review of this research, Scheibehenne et al. (2010) found that the net effect (i.e., the strength) of choice overload is virtually zerothat is, the average effect size reported in papers supporting choice overload is nearly identical to the average effect size in papers finding no support for, or alternatively the reverse of choice overload. As Scheibehenne et al. noted, in order to explain the effect of choice overload, it is essential to search for moderators.

To this end, I build off and extend previous investigations of choice overload as well as answer Scheibehenne et al.'s call by investigating whether a hitherto unexplored moderator, self-other decision making, influences choice overload. Using regulatory focus theory (Higgins, 1987, 1997), I propose that personal decision makers are prevention focused and therefore motivated to reduce contact with unsatisfying options (i.e., errors of commission), whereas proxy decision makers are promotion focused and therefore motivated to reduce non-contact with satisfying options (i.e., errors of omission). Because choice arrays are respectively extensive and limited on account of the number of commissions (i.e., options that are present) and omissions (i.e., options that are absent), I predict that personal decision makers experience choice overload (i.e., less satisfaction after choosing among many options), whereas proxy decision makers experience a reversal of choice overload (i.e., more satisfaction after choosing from many options).

\section{Research on Choice Overload and Regulatory Focus}

A considerable amount of research has been carried out on choice overload (Diehl \& Poynor, 2010; Fasolo, McClelland, \& Todd, 2007; Gourville \& Soman, 2005; Iyengar \& Lepper, 2000; Mick, Broniarczyk, \& Haidt, 2004; Mogilner, Rudnick, \& Iyengar, 2008; Reutskaja \& Hogarth, 2009; Scheibehenne, Greifeneder, \& Todd, 2009; Schwartz, 2000; Sela, Berger, \& Liu, 2009; Shah \& Wolford, 2007). For example, in one study, Iyengar, Huberman, and Jiang (2004) reported that employees' 401(k) contributions drop by thousands of dollars as individuals' organizations add more plans for employees' selection-presumably because selecting among extensive choices is demotivating. In another study, Chernev (2003) found that people who make decisions among many choices are less confident in their decisions, and in fact, more likely to change their decisions than people who make decisions among few choices. Although much research has investigated choice overload, the research has focused on only one particular type of decision - a decision made for the self — and has not yet explored how the availability of choice affects decisions that people make for others. This is a critical distinction because in the real world, important decisions are often made on behalf of others (Yates, 1990). Moreover, these decisions occur in an incredible range of contexts: CEOs make decisions on behalf of employees; parents on behalf of their children; lawyers and financial planners on behalf of their clients; doctors on behalf of 
patients; and one spouse on behalf of the other. Perhaps the clearest example of decision making on behalf of others occurs in organizations where managers make decisions on behalf of employees.

With respect to choice overload, Iyengar and Lepper (2000) found that individuals' motivation to make a decision declines as the number of options increases-why would this relation not extend, and in fact go in reverse, in decisions for others? Shedding light on this question, Crowe and Higgins (1997) asserted that individuals' level of motivation, according to regulatory focus, varies to the degree that individuals orient away from the presence of a negative outcome (error of commission), or alternatively, away from the absence of a positive outcome (error of omission). Thus, among individuals in a promotion focus who are sensitive to committing errors of omission, a limited array should indicate that satisfying options are absent, whereas among individuals in a prevention focus who are sensitive to committing errors of commission, an extensive array should indicate that unsatisfying options are present. In this vein, a promotion-focused individual will feel more satisfied after choosing from an extensive array because an extensive array precludes errors of omission (i.e., "With so many items available, good items must also be available"). In contrast, a prevention-focused individual will feel less satisfied after choosing from an extensive array because an extensive array produces errors of commission (i.e., "With so many items available, bad items must also be available"). Said differently, the difference in satisfaction between an extensive array and a limited array depends on individuals' orientation toward outcomes that are positive (i.e., "good items") or away from outcomes that are negative (i.e., "bad items").

In short, research has shown that people process different amounts of information according to whether they make choices for themselves or for others, and hence, make choices that are different (Polman, 2010; Polman \& Emich, 2011). Considering this, it stands to reason that the ilk of information that individuals use before making choices is also different. However, virtually no work has investigated whether people attend to qualitatively different information according to whether they are deciding for themselves or for others. Beisswanger et al. (2003) and Jonas et al. (2005) found that proxy decision makers occupied themselves more with positive information than do personal decision makers. I extend their findings by positing that regulatory focus theory explains why proxy and personal decisions direct attention to positive and negative information respectively, and I examine the implications this has on decision making, in particular, choice overload.

\section{Overview of Studies}

The current research examines self-other decision making in a choice overload context, and investigates whether post-choice satisfaction and regulatory focus vary according to decision maker role (personal vs. proxy) and how many choices are available (many vs. few). In Study 1, participants chose paint swatches with the prediction that among participants who choose for somebody else, a reversal of the choice overload effect would be observed. Study 2 investigates and extends the findings from Study 1 to a field setting. Customers from two different wine stores varying in size (small vs. large) were asked whether they were buying wine for themselves or for others, and how satisfied they were with their purchases. Next, Studies $3 \mathrm{a}$ and $3 \mathrm{~b}$ were carried out, with two goals in mind. The first goal was to replicate the results of Studies 1 and 2 using different manipulations and measures. The second goal was to test whether regulatory focus causally mediates the relation between self-other decision making and choice overload. Spencer, Zanna, and Fong (2005) proposed that strong inferences of a causal chain can be made if the independent variable and mediating variable are both manipulated. To that end, self-other decision making was manipulated in Study $3 \mathrm{a}$ and regulatory focus was manipulated in Study 3b. In the next two studies, two potential moderators relevant to self-other decision making were tested. Study 4 examined decision makers who choose for close others versus distant others, and Study 5 examined decision makers who choose under conditions of high accountability versus low accountability. Across studies, participants faced four different kinds of choices (viz. paint swatches, wine, ice cream flavors, school courses); furthermore, these choices ranged from hypothetical to real. In sum, I predict that choices for others produce a reversal of the choice overload effect (Studies 1 and 2) - on account of the different regulatory focus that is elicited by people who make choices for themselves and for others (Studies 3-5) - and that social distance and accountability moderate this relationship (Studies 4 and 5).

\section{Study 1}

In this first study, participants were instructed to choose a paint color from either a limited array or an extensive array of paint swatches. Half of the participants made selections for themselves, the other half made selections for somebody else. The main dependent measure was participants' post-choice satisfaction.

\section{Method}

Participants and procedure. One hundred and twenty-five undergraduates (68 women) agreed to participate in exchange for extra credit. Provided with paint swatches, participants were asked to select a color that they would like to use in either their bedroom or somebody else's bedroom. The number of colors that participants could choose from varied, such that participants could choose among either 8 colors or 35 colors. After selecting a paint color, participants answered two questions from 1 (not at all) to 9 (extremely) that measure satisfaction ("How satisfied are you with the paint color you picked?" and "How much do you regret choosing the color you selected?"). After reverse scoring the second question, these items were combined into one scale ( $r=$ $.91, p<.01)$.

\section{Results}

I hypothesized an interaction between choice array and for whom an individual is choosing with respect to how satisfied individuals are with their final choices. In order to test this, I conducted a 2 (decision maker role: personal vs. proxy) $\times 2$ (choice array: few vs. many) ANOVA on participants' satisfaction, which revealed the predicted significant interaction, $F(1,121)=$ 9.63, $p<.01, \eta^{2}=.07$. Participants who chose for themselves reported more satisfaction after they were presented with few 
options $(M=6.65)$ compared to many options $(M=5.84), F(1$, $63)=4.93, p<.05, \eta^{2}=.07$; this is consistent with Iyengar's research on the choice overload effect (Iyengar \& Lepper, 2000). However, as I predicted, the reverse occurred among participants who chose for others. Faced with making a choice for someone else, participants reported more satisfaction after they chose among many options $(M=7.10)$ compared to few options $(M=$ 6.28), $F(1,58)=4.71, p<.05, \eta^{2}=.08$. No main effects were significant; however, a marginal effect of decision maker role showed that participants who chose for others experienced slightly more satisfaction $(M=6.69)$ compared to participants who chose for themselves $(M=6.25), F(1,121)=1.70, p=.09, \eta^{2}=.02$.

\section{Discussion}

These findings suggest that choosing for others produces a reversal of the choice overload effect. Individuals who chose for others were more satisfied after choosing among many options compared to few options. Conversely, individuals who chose for themselves were more satisfied after choosing among few options compared to many options. Research on regulatory focus can potentially explain these findings. The role of regulatory focus was examined further in Studies 3-5, but before reporting on those studies, Study 2 was carried out to determine if the results from Study 1 would apply to a field setting.

\section{Study 2}

This study was carried out to replicate the findings from Study 1 , as well as examine if the findings extend beyond the laboratory. In this study, customers from both a small and a large wine store were approached and asked about their satisfaction with their wine purchases, as well as for whom they were purchasing (self vs. other). A study such as this one is pertinent to the present work because the persons for whom choices were made were real and the choices were willfully conducted. In contrast, the choices and decision maker roles in Study 1 might be considered ambiguous, being that the choices and decision maker roles were hypothetical. Study 2 overcomes this limitation by testing the hypotheses in a scenario with real choices.

\section{Method}

Sample and procedure. Sixty-eight customers from two wine stores in a small city (population $=29,000$ ) in upstate New York were approached and asked if they would be willing to answer two short questions about their wine purchases. Sixty of those customers (33 women) agreed, signifying a response rate of $88 \%$. The wine stores differed according to size and stock. The small store-representing a decision with few choices-is about 400 square feet; the large store-representing a decision with many choices-is roughly ten times the size of the small store. Interviews at each store were conducted one week apart on a Saturday from 4 to 6 PM. Exactly 30 data points were collected at each store; although there were no differences between stores with respect to the number of male or female customers, or for whom customers were buying, there was an overall difference for whom customers were buying such that customers from both stores were more likely to purchase wine for themselves $(M=0.70)$ than for others $(M=0.30), \chi^{2}(1, N=60)=9.60, p<.01, \eta^{2}=.16$.

Measures. Upon agreeing to participate, customers were asked two questions that were counterbalanced. One question was about the person(s) whom the wine was for, "Did you buy the wine for yourself or for somebody else?" The other question was about customers' satisfaction, "On a scale from one to eleven-from not satisfied to extremely satisfied-how would you rate your satisfaction with your purchase?" The experimenter recorded customers' answers as well as their gender and then debriefed each customer by explaining the hypotheses of the study.

\section{Results}

Preliminary analyses showed that order of questions and gender of customer did not predict customers' satisfaction or for whom they were buying wine $\left(F_{\mathrm{S}}<1\right)$; thus the data were collapsed across both of these factors.

In keeping with Study 1, I predicted an interaction between the number of available wine choices, and for whom customers were purchasing with respect to the satisfaction customers experience. To test this, I conducted a 2 (decision maker role: personal vs. proxy) $\times 2$ (store size: small vs. large) ANOVA on customers' satisfaction, which revealed the predicted significant interaction, $F(1,56)=24.30, p<.001, \eta^{2}=.30$. Customers who purchased wine for themselves experienced more satisfaction after shopping at the small wine store $(M=8.95)$ compared to the large wine store $(M=6.95), F(1,40)=31.17, p<.001, \eta^{2}=.44$; once again this is consistent with the choice overload effect. However, a reverse choice overload effect occurred among customers who purchased wine for others. Faced with this choice, customers experienced more satisfaction after shopping at the large wine store $(M=9.44)$ compared to the small wine store $(M=8.00)$, $F(1,16)=4.66, p=.05, \eta^{2}=.22$. In addition, the main effect was significant such that participants who chose for others experienced more satisfaction $(M=8.72)$ compared to participants who chose for themselves $(M=7.95), F(1,56)=4.86, p=.05$, $\eta^{2}=.08$.

\section{Discussion}

These findings both replicate and extend those of Study 1 . Post-choice satisfaction varied as a function of the number of choices in an array, and the person for whom one is choosing. Of import, this study took place outside of the laboratory, and thus its major strength lies in replicating the effect in a realistic setting. However, because of this setting, there are some limitations to bear in mind. For example, the number of personal decision makers did not match the number of proxy decision makers; likewise, it is possible that personal and proxy decision makers vary on other unmeasured dimensions such as how much time and money they spent in each store. Moreover, personal and proxy decision makers' preferences (e.g., liking red wine but buying for someone else who likes white wine) or goals (e.g., buying an expensive or unique wine for someone else with the aim of impressing him or her) may have also varied. Finally, there may have been differences in the degree that personal and proxy decisions makers seek or use advice from others (e.g., store employees). Owing to the limitations inherent in field studies-it is not possible to research 
all variables that might be of interest because of both logistical and ethical constraints-potential differences such as these could not be measured, yet they may play a role in both self-other decision making and choice overload. That said, using both laboratory and field methods undoubtedly provides more convincing evidence that greater satisfaction can result after choosing among extensive choices. I suggested that this is because a different regulatory focus is activated among personal and proxy decision makers. The following three studies examine this possibility by showing whether regulatory focus mediates the relation between self-other decision making and choice overload.

\section{Studies 3a and 3b}

In this pair of studies, mediation between self-other decision making and choice overload was tested causally by manipulating both the independent variable (self-other decision making) and mediator (regulatory focus). In Study 3a, participants were asked to respond to scenarios concerning choices they would make for themselves; alternatively, participants were asked to respond to scenarios concerning choices they would make for others. Next, participants responded to items on the Regulatory Focus Questionnaire (RFQ; Higgins et al., 2001) — a validated scale that measures promotion and prevention focus. In Study 3b, participants were induced with either a promotion or a prevention focus and then asked to select among either many or few ice cream flavors. Taken together, the results of Studies $3 \mathrm{a}$ and $3 \mathrm{~b}$ could indicate that self-other decision making influences people's regulatory focus, and that regulatory focus influences choice overload.

\section{Method}

Participants and procedure. Two hundred seven undergraduates agreed to participate in exchange for extra credit. In Study $3 \mathrm{a}$ $(N=117 ; 70$ women $)$, the effect of self-other decision making on regulatory focus was investigated, whereas in Study $3 b(N=90$; 48 women), the effect of regulatory focus on choice overload was investigated. These studies would provide a causal link between self-other decision making, regulatory focus, and choice overload.

In Study 3a, participants were given 11 scenarios from Beisswanger et al. (2003), each describing a choice about a real-life issue. Specifically, participants made choices for a same-sex friend, or for the self. After participants responded to the scenarios, they filled out the RFQ (cf. Higgins et al., 2001), an 11-item questionnaire that measures promotion focus and prevention focus.

In Study 3b, the mediator was manipulated. Specifically, regulatory focus was manipulated by asking participants to write a brief essay about their hopes and aspirations, or alternatively, their duties and obligations (Higgins, Roney, Crowe, \& Hymes, 1994). In order to induce a promotion focus, participants were asked to think about how their current hopes and aspirations are different now from what they were when they were growing up, as well as what accomplishments they would ideally like to meet at this point in their life. In contrast, to induce a prevention focus, participants were asked to think about how their current duties and obligations are different now from what they were when they were growing up, as well as what responsibilities they think they ought to meet at this point in their life. After writing their essays, participants were presented with pictures of different flavors of ice cream, and asked to select a flavor that they would choose for themselves. The number of flavors that participants could choose from varied, such that participants could choose among either 8 flavors or 35 flavors. After selecting an ice cream flavor, participants answered the same questions measuring satisfaction from Study $1(r=.88, p<.01)$, in addition to three items measuring overload. Specifically, participants indicated to what extent they felt overwhelmed; confused in the decision process; and how difficult it was for them to decide which ice cream to choose (cf. Diehl \& Poynor, 2010). The overload items, which were anchored from 1 (not at all) to 9 (extremely), demonstrated high reliability $(\alpha=.81)$.

\section{Results and Discussion}

The primary dependent variables for Studies $3 \mathrm{a}$ and $3 \mathrm{~b}$ are the reported levels of promotion and prevention among proxy and personal decision makers (Study 3a), and the levels of satisfaction and overload among promotion-focused and prevention-focused participants (Study 3b). In Study 3a, although promotion focus was not correlated with prevention focus, I controlled for each respective regulatory focus in the analyses. As predicted, proxy decision makers reported more promotion focus $(M=22.59)$ than personal decision makers $(M=21.19), F(1,115)=5.57, p<.05, \eta^{2}=.05$. Moreover, personal decision makers reported more prevention focus $(M=17.32)$ than proxy decision makers $(M=15.98), F(1$, $115)=3.92, p<.05, \eta^{2}=.03$. Thus, the results of Study $3 \mathrm{a}$ support the link between self-other decision making and regulatory focus-proxy decision making is related to promotion focus, whereas personal decision making is related to prevention focus. Would, however, regulatory focus predict choice overload?

Study $3 \mathrm{~b}$ investigated this possibility. In particular, I conducted two separate 2 (regulatory focus: prevention vs. promotion) $\times 2$ (choice array: few vs. many) ANOVAs; one on participants' satisfaction and another on participants' overload. Both of them revealed the predicted significant interactions, $F(1,86)=24.42$, $p<.001, \eta^{2}=.22$ for satisfaction; $F(1,86)=8.51, p<.01, \eta^{2}=$ .22 for overload. In addition, a main effect of choice array evidenced for overload, $F(1,86)=2.92, p<.01, \eta^{2}=.09$. Not surprisingly, participants experienced greater overload after choosing among many options $(M=3.83)$ compared to choosing among few options $(M=2.94)$. However, with respect to the interactions, prevention-focused participants experienced more satisfaction and less overload after selecting among few ice cream flavors $\left(M_{\text {satisfaction }}=8.44 ; M_{\text {overload }}=2.55\right)$ than among many ice cream flavors $\left(M_{\text {satisfaction }}=7.53 ; M_{\text {overload }}=4.33\right), F(1,40)=9.42, p<$ $.01, \eta^{2}=.19$ for satisfaction; $F(1,40)=16.81, p<.001, \eta^{2}=$ .30 for overload. As expected, the reverse occurred among promotion-focused participants; they experienced more satisfaction (yet the same amount of overload) after selecting among many ice cream flavors $\left(M_{\text {satisfaction }}=8.22 ; M_{\text {overload }}=3.33\right)$ than among few ice cream flavors $\left(M_{\text {satisfaction }}=7.41 ; M_{\text {overload }}=\right.$ 3.32), $F(1,46)=16.56, p<.001, \eta^{2}=.26$ for satisfaction; $F<$ .20 for overload. Why participants experienced the same level of overload-i.e., the same amount of "overwhelming," "confusion," and "difficulty"-is an open question. I suggest that these items may relate more to the structure of the assortments (i.e., how the choices are presented), in contrast to the number of choices presented. For example, Scheibehenne et al. (2010) suggest that how items are categorized makes items more or less difficult and 
confusing to process, and ultimately influences choice overload (Mogilner, Rudnick, \& Iyengar, 2008). In the current studies, categorization is kept constant in both the "many options" and "few options" conditions-so there may not be reason to suspect differences among the overload items because the choice environment is the same between conditions. Also, there may not have been enough options to observe meaningful differences among the items. That is, choosing among 35 flavors of ice cream may not produce much overload since the highest amount of overload that was found was 3.83 out of 9 , well below the midpoint. Thus, it could be that 35 options of ice cream flavors are too few to feel sufficiently overloaded. Finally, the satisfaction items are more affectively laden than the overload items - and people might be extra sensitive to changes that influence affect in comparison to other changes, considering how frequently and quickly people change their moods (Larsen, 1987).

In all, the results of Study $3 \mathrm{~b}$ support the link between regulatory focus and choice overload (when assessed by items measuring satisfaction)-prevention focus is related to experiencing choice overload, whereas promotion focus is related to experiencing a reversal of choice overload. These findings provide evidence for the relation between self-other decision making and choice overload, and in particular, the mediating role of regulatory focus. To extend on this finding, Studies 4 and 5 were carried out to investigate potential variables that moderate this relationship, as well as include statistical tests of mediation (Study 5).

\section{Study 4}

In this study, self-construal and by extension social distance between self and other were manipulated. By social distance, I mean how close others are seen to the self (Liberman, Trope, \& Stephan, 2007), and I begin with the assumption that self-construal is a form of social distance. Self-construal describes the extent that others are included into the self-concept (Cross, Bacon, \& Morris, 2000; Cross, Hardin, \& Gercek-Swing, 2011). For example, people include in-group others into the self-concept, and exclude outgroup others (Turner, Oakes, Haslam, \& McGarty, 1994). In Schubert and Otten's (2002) words, "we distance ourselves from a group or are in the inner circle" (p. 353). In the current research, I propose that self-construal and social distance are related-such that an interdependent self-construal, in which others are more likely to be included into the self-concept, is related with low social distance; whereas an independent self-construal, in which others are less likely to be included into the self-concept, is related with high social distance. This matches with existing definitions of social distance; for example, (more) social distance is associated “to people less and less like oneself” (Trope, Liberman, \& Wakslak, 2007, p. 84).

As the social distance between the self and others changes, so too does the level of regulatory focus (Pennington \& Roese, 2003). That is, a promotion focus is related to high social distance, whereas a prevention focus is related to low social distance (Mogilner, Aaker, \& Pennington, 2008). In order to manipulate social distance, participants were led to include others into their concept of the self (e.g., Polman \& Emich, 2011). In particular, participants were primed with either an interdependent selfconstrual (low social distance) or an independent self-construal (high social distance) by circling pronouns in a supplied text (e.g.,
Gardner, Gabriel, \& Lee, 1999; Kühnen \& Oyserman, 2002). Based on research showing that an interdependent self-construal is related to more emphasis on prevention-focused information (Lee, Aaker, \& Gardner, 2000), I expect that among participants with low social distance between self and other, choices for others would be prevention focused; hence choice overload would be observed among both personal and proxy decision makers.

\section{Method}

Participants and procedure. Sixty-nine undergraduates (40 women) agreed to participate in exchange for extra credit. Participants were instructed to read a paragraph detailing a child's rendition of a family trip to Costa Rica, and simultaneously circle pronouns contained within the story. In half of the stories, pronouns were independent (e.g., I, me, my); in the other half, pronouns were interdependent (e.g., we, us, our). Research has shown that circling interdependent pronouns elicits inclusion of others into the concept of the self (i.e., low social distance between self and others), and likewise, circling independent pronouns prevents inclusion of others into the concept of the self (i.e., high social distance between self and others; Gardner et al., 1999; Kühnen \& Oyserman, 2002).

After circling pronouns, participants were given materials with paint swatches and asked to select one. Both the number of paint swatches (8 vs. 35) and for whom participants were deciding (self vs. other) differed, such that, as in Study 1, participants selected among either many options or few options, for either their bedroom or somebody else's bedroom.

Measures. Participants completed three items measuring satisfaction $(\alpha=.71)$ : "How satisfied are you with the paint color you picked?" "How much do you regret choosing the color you selected?" and "How satisfied do you think you would be if you actually painted your room the color you selected?" Each item was rated on a scale from 1 (not at all) to 9 (extremely), and the second item was reverse scored.

Following these questions, participants responded to items designed to measure regulatory focus created by van Stekelenburg (2006) and used in other research (e.g., Faddegon, Scheepers, \& Ellemers, 2008). From 1 (not at all) to 7 (very much), participants responded with their level of agreement to 14 proverbs-half of which are promotion focused (e.g., "Where there's a will, there's a way"; $\alpha=.79$ ) and half of which are prevention focused (e.g., "Act normal, that's crazy enough"; $\alpha=.65$ ). High agreement among promotion-focused proverbs indicates one is in a promotion focus, whereas high agreement among prevention-focused proverbs indicates one is in a prevention focus. Finally, all participants completed a check on their self-construal by writing 20 statements about themselves. In the same manner as Cousins (1989), participants completed the sentence, "I am ... " 20 different times, and the number of interdependent statements (e.g., "I am a sister") plus independent statements (e.g., "I am extroverted") was counted.

\section{Results}

Results indicate that the manipulation of self-construal was successful. Two coders blind to the experimental conditions and hypotheses coded each statement according to Cousins' (1989) recommendations. The coders agreed on $89 \%$ of the responses 
(moreover, a kappa statistic was calculated to control for agreement due to chance; kappa was 0.69). Because the coders demonstrated significant agreement in their ratings of the statements, their assessments were averaged together to form one score for each self-construal. In particular, participants primed with low social distance between self and other generated proportionally more statements related to interdependence $(M=0.20)$ than participants primed with high social distance between self and other $(M=0.12), F(1,66)=7.78, p<.01, \eta^{2}=.10$. Likewise, participants primed with low social distance between self and other generated proportionally fewer statements related to independence $(M=0.66)$ than participants primed with high social distance between self and other $(M=0.89), F(1,66)=8.88$, $p<.01, \eta^{2}=.12$.

Satisfaction. A 2 (decision maker role: personal vs. proxy) $\times$ 2 (choice array: few vs. many) $\times 2$ (social distance: low vs. high) ANOVA on satisfaction failed to yield a significant three-way interaction, $F(1,61)=2.76, p=.10, \eta^{2}=.11$. However, separate analyses for low and high social distance participants yielded significant results (see Table 1 for means). A 2 (decision maker role: personal vs. proxy) $\times 2$ (choice array: few vs. many) ANOVA among high social distance participants revealed a significant interaction, $F(1,36)=6.91, p<.05$, $\eta^{2}=.16$, indicating that high social distance participants who chose for themselves reported more satisfaction after choosing among few options $(M=$ $6.73)$ compared to many options $(M=5.92), F(1,61)=3.79, p=$ $.05, \eta^{2}=.16$. Yet, among participants who chose for others, the reverse was observed; high social distance participants reported more satisfaction after choosing among many options $(M=6.80)$ compared to few options $(M=5.95), F(1,61)=4.32, p<.05$, $\eta^{2}=.18$. Thus, among high social distance participants, the predicted pattern of the choice overload effect and reverse choice overload effect was observed.

I predicted that because low social distance individuals incorporate others into their concept of the self (Triandis, 2001), they would evidence a prevention focus (Lee et al., 2000) and choose for others as they would choose for themselves. If so, then I expect low social distance individuals to experience choice overload in choices for both others and themselves. In other words, instead of an interaction, I expect a main effect of choice array. A 2 (decision maker role: personal vs. proxy) $\times 2$ (choice array: few vs. many) ANOVA among low social distance participants revealed a significant main effect of choice array, $F(1,24)=5.60, p<.05, \eta^{2}=.19$. The interaction was not significant $(F<1)$. Regardless of whether a choice was for the self or somebody else, low social distance participants experienced more satisfaction after choosing among few options $(M=6.78)$ compared to many options $(M=6.00)$.

Regulatory focus. I predicted that personal decision makers are in a prevention focus, and that proxy decision makers are in a promotion focus. Consistent with past research, prevention focus and promotion focus were correlated $(r=.26, p<.05$; e.g., Semin, Higgins, de Montes, Estourget, \& Valencia, 2005) so I controlled for each respective focus in the analyses. To test the first prediction, a 2 (decision maker role: personal vs. proxy) $\times 2$ (choice array: few vs. many) $\times 2$ (social distance: low vs. high) ANOVA on prevention was conducted and revealed a main effect of social distance, $F(1,60)=$ 7.29, $p<.01, \eta^{2}=.11$, as would be expected given past research showing that low social distance (i.e., interdependent) individuals heed prevention-related information more than promotion-related information (Lee et al., 2000). Indeed, low social distance participants endorsed prevention-focused proverbs more $(M=4.58)$ than high social distance participants $(M=3.88)$. Of particular interest here is the main effect of decision maker role, $F(1,60)=5.47, p<.05, \eta^{2}=$ .08. Personal decision makers endorsed prevention-related proverbs more $(M=4.92)$ than proxy decision makers $(M=3.96)$. Although the interaction between decision maker role and social distance was not significant $(F<2.5)$, a simple effects test revealed that among personal decision makers, greater endorsement of preventionrelated proverbs was observed among low social distance participants $(M=5.01)$ than among high social distance participants $(M=3.98), F(1,36)=11.90, p<.001, \eta^{2}=.25$.

To test the second prediction- that proxy decision makers are in a promotion focus - a 2 (decision maker role: personal vs. proxy) $\times 2$ (choice array: few vs. many) $\times 2$ (social distance: low vs. high) ANOVA on promotion was conducted and revealed a main effect of decision maker role, $F(1,60)=4.65, p<.05, \eta^{2}=$ .07 . As predicted, proxy decision makers endorsed promotionrelated proverbs more $(M=5.47)$ than personal decision makers $(M=4.27)$. No other effects were significant.

\section{Discussion}

This study extends the previous studies in several ways. First, evidence for the choice overload effect was found, but so was additional evidence for a reverse choice overload effect. Personal decision makers were less satisfied after choosing among many

Table 1

Effects of Decision Maker Role and Choice Array on Satisfaction Among Participants in Study 4 and Study 5

\begin{tabular}{|c|c|c|c|c|c|c|}
\hline \multirow[b]{3}{*}{ Study } & \multicolumn{6}{|c|}{ Satisfaction } \\
\hline & \multicolumn{3}{|c|}{ Personal decision makers } & \multicolumn{3}{|c|}{ Proxy decision makers } \\
\hline & $\begin{array}{l}\text { Many } \\
\text { options }\end{array}$ & $\begin{array}{l}\text { Few } \\
\text { options }\end{array}$ & $\begin{array}{l}\text { Choice overload/reverse } \\
\text { choice overload }\end{array}$ & $\begin{array}{l}\text { Many } \\
\text { options }\end{array}$ & $\begin{array}{l}\text { Few } \\
\text { options }\end{array}$ & $\begin{array}{l}\text { Choice overload/reverse } \\
\text { choice overload }\end{array}$ \\
\hline \multicolumn{7}{|l|}{ Study 4} \\
\hline High social distance participants & 5.92 & 6.73 & Choice overload & 6.80 & 5.95 & Reverse choice overload \\
\hline Low social distance participants & 5.93 & 6.75 & Choice overload & 6.01 & 6.82 & Choice overload \\
\hline \multicolumn{7}{|l|}{ Study 5} \\
\hline Non-accountable participants & 6.35 & 7.14 & Choice overload & 7.23 & 6.61 & Reverse choice overload \\
\hline Accountable participants & 6.05 & 7.11 & Choice overload & 6.11 & 7.15 & Choice overload \\
\hline
\end{tabular}


options compared to few options; however, proxy decision makers were more satisfied after choosing among many options compared to few options. In addition, the effect of social distance was found to moderate whether people experience choice overload. Primed with low social distance, participants felt overloaded by extensive options in both choices for themselves and others-because these participants felt psychologically close to others and included others into their concept of the self. Consequently, low social distance participants were in a prevention focus and made choices for others as they would make choices for themselves. In contrast, participants primed with high social distance between self and other only experienced choice overload in choices for themselves, and likewise, experienced reverse choice overload in choices for others. In light of these findings, personal decision makers were found to be in a prevention focus, whereas proxy decision makers were found to be in a promotion focus.

\section{Study 5}

Study 5 continues this research by investigating the effect of accountability on self-other decision making and choice overload. I also test whether regulatory focus statistically mediates the relationship between self-other decision making and choice overload. Research has shown that as the level of accountability shifts, so too does the level of regulatory focus (Crowe \& Higgins, 1997). That is, when people are held accountable, attention is drawn to prevention-focused information (e.g., fear, guilt, regret, caution; Crowe \& Higgins, 1997). As an example, Casarett and Ross (1997) found that doctors sometimes make cautious choices for their patients that are not consistent with patients' predilections, for fear of feeling guilty after making choices that are consistent with patients' preferences. In testing this possibility, Study 5 comprised students selecting courses for a following semester. As in the preceding studies, the array of choices and decision maker role varied, such that students selected among either a small array or a large array of courses for either themselves or somebody else. In addition, accountability was manipulated by informing half of the students that they would have to justify their choices to the professor of their class; the other half of students were instructed to justify their choices, but to no one in particular. Afterward, all participants completed the same check on regulatory focus that was used in Study 4, and answered questions dealing with the satisfaction with their class choices. Based on research showing that accountability is related to more emphasis on preventionfocused information (Crowe \& Higgins, 1997), I expect that a prevention focus will activate among decision makers who feel accountable for their choices; hence choice overload would be observed among both personal and proxy decision makers.

\section{Method}

Participants and procedure. One hundred and eighty-one undergraduates ( 89 women) agreed to participate in exchange for extra credit. Participants were instructed that they would be taking part in a study on selecting courses for the following semester. In particular, courses were drawn from an array of business-related offerings from participants' university course roster. Before participants selected courses, they were presented with a disclaimer that elicited one of two levels of accountability. For half of the participants, the disclaimer revealed that participants would be instructed to later justify their choices and that their professor (all participants were drawn from the same class) would read each participant's justifications. For the other half of participants, the disclaimer was the same, barring the part of participants' professor reading each participant's justifications. Thus, in both conditions participants justified their choices, but in only one condition did participants think their professor would read their justifications. After reading the disclaimer, participants made their course selections. As in the previous studies, participants selected for either themselves or somebody else; moreover, participants selected among either many courses (60) or few courses (16). In a departure from the previous studies, participants selected two options. After making their selections, participants justified their choices and then responded to the same satisfaction questions $(\alpha=.73)$ and regulatory focus measures $(\alpha=.79$ for promotion focus; $\alpha=.70$ for prevention focus) used in Study 4, as well as a manipulation check on accountability ("How concerned are you that your choices will be evaluated by others?"). Participants responded from 1 (not at all) to 9 (extremely).

\section{Results}

Results indicate that the manipulation of accountability was successful. Among participants who were instructed that the professor would read their justifications, concern that their choices would be evaluated by others was greater $(M=4.43)$ than among participants who were not instructed that the professor would read their justifications $(M=2.29), F(1,174)=6.28$, $p<.001, \eta^{2}=.18$.

Satisfaction. A 2 (decision maker role: personal vs. proxy) $\times$ 2 (choice array: few vs. many) $\times 2$ (condition: accountable vs non-accountable) ANOVA on satisfaction yielded a significant main effect of choice array, $F(1,166)=7.30, p<.01, \eta^{2}=.04$, indicating that participants who chose among few options experienced more satisfaction $(M=7.08)$ than participants who chose among many options $(M=6.58)$. However, this effect was qualified by two interactions. The first interaction demonstrated accountability moderates the effect of choice array on satisfaction, $F(1,166)=5.13, p<.05, \eta^{2}=.03$, such that among accountable participants, satisfaction was lower after choosing among many options $(M=6.34)$ compared to few options $(M=7.27), F(1$, $88)=13.18, p<.001, \eta^{2}=.13$. Among non-accountable participants, however, no difference was observed $(F<1)$. The second interaction, and the one of particular interest here, is the significant three-way interaction, $F(1,166)=4.65, p<.05, \eta^{2}=$ .03. To analyze it, separate analyses were performed for accountable and non-accountable participants (see Table 1 for means). A 2 (decision maker role: personal vs. proxy) $\times 2$ (choice array: few vs. many) ANOVA among non-accountable participants revealed a significant interaction, $F(1,80)=6.89, p<.05, \eta^{2}=.08$, indicating that non-accountable participants who chose for themselves reported more satisfaction after choosing among few options $(M=7.14)$ compared to many options $(M=6.35), F(1$, 79) $=8.47, p<.01, \eta^{2}=.10$. Yet, among participants who chose for others, the reverse was observed; non-accountable participants reported more satisfaction after choosing among many options $(M=7.23)$ compared to few options $(M=6.61), F(1,82)=5.95$, $p<.05, \eta^{2}=.07$. Thus, among non-accountable participants, the 
predicted pattern of the choice overload effect was observed, yet in choices for others, participants experienced a reverse choice overload effect.

I predicted that accountability would moderate the relationship between self-other decision making and choice overload because accountability leads to experiencing a prevention focus (Crowe \& Higgins, 1997). I thus expect accountable participants to experience choice overload in choices for both others and themselves. In other words, instead of an interaction, I would expect a main effect of choice array. A 2 (decision maker role: personal vs. proxy) $\times 2$ (choice array: few vs. many) ANOVA among accountable participants revealed a significant main effect of choice array, $F(1$, $86)=12.67, p<.01, \eta^{2}=.13$. Moreover, the interaction was not significant $(F<1)$. Thus, it would appear that for accountable participants, choices for the self resembled choices for others. Regardless of whether a choice was for the self or somebody else, participants experienced more satisfaction after choosing among few options $(M=7.29)$ compared to many options $(M=6.36)$.

Mediation analysis. I carried out two bootstrapping procedures among the non-accountable participants to determine (a) whether promotion focus mediates the relation between deciding for others and feeling more satisfied after choosing among many options, and (b) whether prevention focus mediates the relation between deciding for the self and feeling more satisfied after choosing among few options. Consistent with Preacher and Hayes' (2004) guidelines, mediation was tested by deriving bias-corrected and accelerated confidence intervals for the indirect effect of self-other decision making on individuals' satisfaction after choosing among many choices, through the respective regulatory focus mediator (promotion focus and prevention focus were correlated, $r=.25, p<.001$, so I controlled for each respective focus). One thousand repeated random samples were taken from the original data to compute the indirect effects. Mediation is said to occur if the derived confidence interval does not contain zero. Results of the bootstrap analyses indicated that the true indirect effect was estimated to lie between -.58 and -.04 for choices for others (while controlling for prevention focus), and between .03 and .38 for choices for the self (while controlling for promotion focus), with $95 \%$ confidence. Neither confidence interval contains zero, confirming that promotion and prevention focus did act as the respective mediators - verified also by two separate Sobel tests $(z=2.13, p<.05$ for choices for others; $z=2.18, p<.05$ for choices for the self).

\section{Discussion}

The findings from this study provide converging evidence that the effects of choice overload are reversed among proxy decision makers, and suggest that these effects are moderated by felt accountability. Moreover, I found that regulatory focus mediated the relationship between self-other decision making and choice overload. Among personal decision makers, greater satisfaction was experienced in choices with few options compared to choices with many options-in other words, the choice overload effect was observed. However, the reverse was observed among proxy decision makers. In this case, greater satisfaction was experienced in choices with many options compared to choices with few options. That said, among people who were accountable for their choices, the reverse choice overload effect was absent. Instead, in both choices for the self and others, choice overload was present. Why? It was suggested that self-other decision making varies with regulatory focus. As predicted, among personal decision makers, a prevention focus was evidenced and thus choice overload was experienced; whereas among proxy decision makers, a promotion focus was evidenced and thus reverse choice overload was experienced. However, among participants who were induced to feel accountability, a prevention focus was evidenced; thus I observed choice overload among both personal and proxy decision makers.

As a secondary contribution, Study 5 continues the research on choice overload by examining a context in which people make more than one choice. Research on choice overload typically comprises instructions to select and make one single choice. But choices in real life may not be as simple. For example, in thinking about what to make for dinner, an individual may make several choices, such as deciding which ingredients to use and which entrée to make, that altogether culminate into one ultimate choice. As in the current study, students selected more than one course that would form their overall course load. In this vein, the current study demonstrates that the choice overload effect-as well as the reverse choice overload effect-operates in contexts in which people make multiple choices. Evidently, the opportunity to secure more alternatives does not eliminate the choice overload effect.

\section{General Discussion}

The current series of experiments address whether a reverse choice overload effect is observed in choices for others, and whether regulatory focus mediates this relationship. In five studies, including a field study, both a choice overload effect and a reverse choice overload effect were evidenced. Contrary to the findings of Iyengar and Lepper (2000), the present research demonstrates a clear example of when more choice satisfies in comparison to less choice. When participants chose for others, decisions comprising more paint swatches (Studies 1 and 4), more wine (Study 2), more flavors of ice cream (Study 3), and more school courses (Study 5) were more satisfying than decisions comprising fewer of these choices. Owing to the fact that a choice for somebody else activates a promotion focus and hence a motivation to reduce errors of omission, individuals experienced greater satisfaction after choosing among many options. Likewise, because a choice for the self activates a prevention focus and hence a motivation to reduce errors of commission, individuals experienced less satisfaction after choosing among many options.

Along these lines, in making choices for others, participants who were primed with low social distance (Study 4) or led to believe that they were accountable for their choices (Study 5) did not show the reverse choice overload effect. Instead, under conditions of low social distance and accountability, a prevention focus was activated, resulting in individuals' choices for others resembling individuals' choices for themselves. These findings are consistent with other research. Lee et al. (2000) found that low social distance was related to a prevention focus; as did Crowe and Higgins (1997) with respect to accountability. Moreover, in a medical study, Zikmund-Fisher et al. (2006) found that proxy decision makers committed fewer errors of omission (e.g., not giving a vaccine) compared to personal decision makers. Together, this evidence provides a strong case that among proxy decision makers, a motivation to reduce errors of omission is present, and 
likewise, among personal decision makers, a motivation to reduce errors of commission is present.

The theoretical implications of the present work reach beyond the context of choice overload. Fundamentally, this research sheds light on the differences between making a choice for the self and making a choice on behalf of somebody else. A handful of earlier studies have investigated choice overload, regulatory focus, and self-other decision making, and the current work makes contributions to these lines of research in three different ways. First, although choice overload is explained by demotivation (Iyengar \& Lepper, 2000), this explanation may be limited to choices that are for the self. Indeed, the current work demonstrates that choice overload is context dependent, such that in cases like making choices for others, choosing among many alternatives is not in itself demotivating, and by the same token, not unsatisfying. In particular, other mechanisms may be used to explain choice overload, as in the present case with regulatory focus. This perspective is not meant to invalidate or replace explanations based on demotivation. Instead, it is meant to complement these accounts by showing choice overload can be produced according to individuals' regulatory focus.

Second, the current work reconciles mixed findings surrounding research on self-other decision making. Research to date has examined whether proxy decision makers make more risky or less risky choices compared to personal decision makers (e.g., Beisswanger et al., 2003; Fernandez-Duque \& Wifall, 2007; Stone et al., 2002; Teger \& Kogan, 1975; Wallach et al., 1964; Wray \& Stone, 2005; Zaleska \& Kogan, 1971). Although this research is inconclusive insofar as choices for others have been found to be both more risky and less risky than choices made for the self, an appeal to regulatory focus informs that it might not be a case of whether choices for others compared to choices for the self differ according to level of risk, but rather, according to a selective focus on positive and negative information. For example, when making a choice for the self, and a prevention focus is activated, a cautious choice (e.g., declining a blind date) might result when an individual anticipates the presence of a negative outcome (e.g., going on a blind date with a boring partner) whereas a risky choice (e.g., continuing to gamble after incurring a loss) might result when an individual anticipates the absence of a negative outcome (e.g., mollifying a loss). Thus, applying regulatory focus to self-other decision making is of particular importance because it reconciles past research into a unifying theory.

Third, because a different regulatory focus evidences among decision makers who choose for themselves compared to others, there may be considerable implications for a wide range of psychological processes in relation to self-other decision making. For example, relative to a prevention focus, a promotion focus has been found to increase creativity, self-control, and success in negotiations (Dholakia, Gopinath, Bagozzi, \& Nataraajan, 2006; Friedman \& Förster, 2001; Galinsky, Leonardelli, Okhuysen, \& Mussweiler, 2005). Likewise, relative to a promotion focus, a prevention focus has been found to increase local processing, independent self-construals, and vigilance (Förster \& Higgins, 2005; Idson, Liberman, \& Higgins, 2000; Lee et al., 2000). It is reasonable to ask, therefore, whether variables such as these also differ according to whether decision makers choose for their own behalves or for others' behalves.
In this vein, future research could investigate whether other studies on self-other decision have relied in some way on regulatory focus to obtain their results, at least in part. For instance, Polman and Emich (2011) found that choices for others are more creative than choices for the self. Moreover, Laran (2010) found that choices for others are more indulgent than choices for the self. Might promotion focus, which increases creativity and indulgent behavior (Dholakia et al., 2006; Friedman \& Förster, 2001), be the underlying driver of these results? Admittedly, this speculation is suggested by the results pattern of the present research rather than tested by their design. The results, however, do encourage further research in regulatory focus and self-other decision making writ large.

\section{Limitations}

Although the research is ripe for investigating self-other decision making, there are limitations to keep in mind. For example, personal decision makers experience the consequences of their choices, but proxy decision makers may not have this (mis)fortune. Put differently, differences in self-other decision making may be attributed to decision makers' sensitivity toward the presence and absence of outcomes, in contrast to the positive or negative nature of outcomes. One way to test this difference is to have decision makers choose on behalf of others, yet still experience the consequences of their choices - such is the case of a decision maker who chooses for his or her group compared to a group that does not include the decision maker as a member (because in the former group, the decision maker experiences the choice consequences, whereas in the latter group the decision maker does not). Zaleska and Kogan (1971) carried out this test and found no between-subject differences between decision makers who choose for groups that include them as members and groups that do not. This suggests that experiencing an outcome may play less of a role in self-other decision making compared to the positive or negative nature of an outcome. Still, the presence and absence of an outcome are important because commensurate with getting to experience an outcome is anticipating it-if an individual chooses for herself, she will potentially consider the extent that she anticipates regretting her choice before ultimately choosing (Zeelenberg, 1999). But if an individual is choosing for somebody else, she may not anticipate regret and therefore preclude it from influencing her choice. That said, participants in Studies 1, 3, 4, and 5 did not actually experience their choices, suggesting that self-other differences in decision making remain even after controlling for the influence of anticipating and experiencing decision outcomes. Nevertheless, future research should directly examine the effect of experiencing an outcome in self-other decision making.

A second limitation of the current research is that it is impossible to know for whom individuals were choosing. On research in social judgment, Epley and Dunning (2000) suggested that individuals make different predictions for strangers or "average persons" than they do for family members or friends (see also Alicke, Klotz, Breitenbecher, Yurak, \& Vredenburg, 1995; Hsee \& Weber, 1997). The same could be said with making choices, such that choices may vary according to whether the other is a close or distant other. This notion dovetails with Study 4, being that the self-construal between the self and other was directly manipulated, 
and different effects on choice overload were observed. Moreover, participants in Study 2 who chose among wines in a store presumably knew for whom they were choosing, yet still experienced reverse choice overload. Likewise, the same results were found in Study 3a, in which participants were instructed to choose for friends. Thus, we might expect differences in self-other decision making according to whom people are choosing (e.g., mother, friend, employee). Future research should directly investigate specific degrees of social distance such as choosing for subordinates or superordinates, among possible other cases such as choosing on behalf of a group (e.g., Redelmeier \& Tversky, 1990; Zaleska \& Kogan, 1971).

Another limitation of the current research is the focus on postchoice satisfaction in contrast to other measures of choice overload. Although investigating satisfaction is common when measuring choice overload, the current research ignores whether choices for the self and others are different in areas other than affect (e.g., satisfaction, regret). Of import, choice overload also impacts the process, content, and quality of choices, in addition to other outcomes such as confidence and participants' likelihood to change their choices. Thus it is an open question how the current results extend to these other variables, particularly because these findings show a reversal on only one aspect of choice overload, rather than on the entire phenomenon itself. Although I did examine other measures such as "overwhelming," "confusing," and "difficulty" (Study 3b), the results were inconclusive-potentially because the range of variables suggested to measure choice overload includes many different affective, cognitive, and behavioral variables, each with its own variable effects on choice overload. Future research should investigate the interaction between these other variables and self-other decision making, as well as other moderators so as to extend the choice overload research beyond variables solely related to satisfaction.

Also potentially worthwhile is considering the extent of effort exerted among people who make choices for others. It is possible that people feel worse about their choices when choices require extensive effort (Garbarino \& Edell, 1997; e.g., "I can't make up my mind"), but feel good about their choices for others when they require extensive effort (e.g., "I did a good deed for this person by carefully thinking this through"). ${ }^{1}$ This is not unlike research based on prosocial motivation-the desire to expend effort to benefit others (Batson, 1987). People who make choices for others may experience the opportunity to have a positive impact on others. In particular, people experience relatedness in connecting their choices to outcomes that matter in the lives of others (Grant, 2007). Indeed, the desire to benefit others has been found to stimulate processing of information, and influence the way individuals attend, encode, and retain information (Grant \& Berry, 2011). This could explain why proxy decision makers introspect on and seek out more information than personal decision makers (Jonas \& Frey, 2003; Jonas et al., 2005; Kray, 2000; Polman, 2010; Polman \& Emich, 2011). Ironically, the more people introspect on their choices, the less likely they are to be satisfied with their choices (Tordesillas \& Chaiken, 1999; Wilson et al., 1993; Wilson \& Schooler, 1991). However, as recent research by Polman (2010) has shown, proxy decision makers experience less post-choice dissonance, and presumably more satisfaction with their choices, despite introspecting more than personal decision makers. This may be because proxy decision making is an interpersonal process that liberates decision makers from second-guessing themselves as well as frees them from brooding over trade-offs, foregone opportunities, and high expectations - the sort of intrapersonal behaviors that subvert systematic processing and cause decision makers to focus on their negative emotions in lieu of their decisions (Schwartz, 2004). We must doubt however, at least until this possibility is tested empirically, whether proxy decision making attenuates indecision and negative emotions among decision makers.

\section{Conclusion}

In conclusion, I found that among personal decision makers, a prevention focus is activated and people are more satisfied with their choices after choosing among few options compared to many options; in other words, individuals experience the choice overload effect. However, among proxy decision makers, a promotion focus is activated and people are more satisfied with their choices after choosing among many options compared to few options; that is to say, individuals experience a reverse choice overload effect.

Given the ubiquity of choices that are made on behalf of others, it is surprising how little research has been conducted on selfother decision making in psychology, marketing, and the management literature writ large. Relatively little is known about how people make choices for other people, yet much is known about decision making in general. This was a natural place to begin, for without some basic understanding of decision making, one stands little chance of understanding the complex case of how people make choices for other people. Work in this area could find that some of the decision heuristics and biases we take for granted are nonexistent or even reversed when a choice is made on behalf of another-such as in the present case for the choice overload effect. In the Bible, Jesus teaches, "Do to others as you would have them do to you" (Luke 6:31). In retrospect, this lesson might be especially difficult to heed considering choices we make for others are different from choices we make for ourselves.

${ }^{1} \mathrm{I}$ thank an anonymous reviewer for making this point.

\section{References}

Alicke, M. D., Klotz, M. L., Breitenbecher, D. L., Yurak, T. J., \& Vredenburg, D. S. (1995). Personal contact, individuation, and the betterthan-average effect. Journal of Personality and Social Psychology, 68, 804-825. doi:10.1037/0022-3514.68.5.804

Anderson, L. K., Taylor, J. T., \& Holloway, R. J. (1966). The consumer and his alternatives: An experimental approach. Journal of Marketing Research, 3, 62-67. doi:10.2307/3149436

Batson, C. D. (1987). Prosocial motivation: Is it ever truly altruistic? In L. Berkowitz (Ed.), Advances in experimental social psychology (Vol. 20, pp. 65-122). New York, NY: Academic Press.

Beisswanger, A. H., Stone, E. R., Hupp, J. M., \& Allgaier, L. (2003). Risk taking in relationships: Differences in deciding for oneself versus for a friend. Basic and Applied Social Psychology, 25, 121-135. doi:10.1207/ S15324834BASP2502_3

Casarett, D., \& Ross, L. F. (1997). Overriding a patient's refusal of treatment after an iatrogenic complication. New England Journal of Medicine, 336, 1908-1910. doi:10.1056/NEJM199706263362611 
Chernev, A. (2003). When more is less and less is more: The role of ideal point availability and assortment in consumer choice. Journal of Consumer Research, 30, 170-183. doi:10.1086/376808

Cousins, S. D. (1989). Culture and self-perception in Japan and the United States. Journal of Personality and Social Psychology, 56, 124-131. doi:10.1037/0022-3514.56.1.124

Cross, S. E., Bacon, P. L., \& Morris, M. L. (2000). The relationalinterdependent self-construal and relationships. Journal of Personality and Social Psychology, 78, 791-808. doi:10.1037/0022-3514.78.4.791

Cross, S. E., Hardin, E. E., \& Gercek-Swing, B. (2011). The what, how, why, and where of self-construal. Personality and Social Psychology Review, 15, 142-179. doi:10.1177/1088868310373752

Crowe, E., \& Higgins, E. T. (1997). Regulatory focus and strategic inclinations: Promotion and prevention in decision-making. Organizational Behavior and Human Decision Processes, 69, 117-132. doi:10.1006/ obhd.1996.2675

Dholakia, U. M., Gopinath, M., Bagozzi, R. P., \& Nataraajan, R. (2006). The role of regulatory focus in the experience and self-control of desire for temptations. Journal of Consumer Psychology, 16, 163-175. doi: $10.1207 /$ s15327663jcp1602_7

Diehl, K., \& Poynor, C. (2010). Great expectations?! Assortment size, expectations and satisfaction. Journal of Marketing Research, 27, 312322.

Eaton, B. C., \& Lipsey, R. G. (1979). Comparison shopping and the clustering of homogeneous firms. Journal of Regional Science, 19, 421-435. doi:10.1111/j.1467-9787.1979.tb00610.x

Epley, N., \& Dunning, D. (2000). Feeling "holier than thou": Are selfserving assessments produced by errors in self- or social prediction? Journal of Personality and Social Psychology, 79, 861-875. doi: 10.1037/0022-3514.79.6.861

Faddegon, K., Scheepers, D., \& Ellemers, N. (2008). If we have the will, there will be a way: Regulatory focus as a group identity. European Journal of Social Psychology, 38, 880-895. doi:10.1002/ejsp.483

Fasolo, B., McClelland, G. H., \& Todd, P. M. (2007). Escaping the tyranny of choice: When fewer attributes make choice easier. Marketing Theory, 7, 13-26. doi:10.1177/1470593107073842

Fernandez-Duque, D., \& Wifall, T. (2007). Actor/observer asymmetry in risky decision making. Judgment and Decision Making, 2, 1-8.

Förster, J., \& Higgins, E. T. (2005). How global versus local perception fits regulatory focus. Psychological Science, 16, 631-636. doi:10.1111/ j.1467-9280.2005.01586.x

Friedman, R. S., \& Förster, J. (2001). The effects of promotion and prevention cues on creativity. Journal of Personality and Social Psychology, 81, 1001-1013. doi:10.1037/0022-3514.81.6.1001

Galinsky, A. D., Leonardelli, G. J., Okhuysen, G. A., \& Mussweiler, T. (2005). Regulatory focus at the bargaining table: Promoting distributive and integrative success. Personality and Social Psychology Bulletin, 31, 1087-1098. doi:10.1177/0146167205276429

Garbarino, E. C., \& Edell, J. A. (1997). Cognitive effort, affect, and choice. Journal of Consumer Research, 24, 147-158. doi:10.1086/209500

Gardner, W. L., Gabriel, S., \& Lee, A. Y. (1999). "I" value freedom, but "we" value relationships: Self-construal priming mirrors cultural differences in judgment. Psychological Science, 10, 321-326. doi:10.1111/ $1467-9280.00162$

Gourville, J. T., \& Soman, D. (2005). Overchoice and assortment type: When and why variety backfires. Marketing Science, 24, 382-395. doi:10.1287/mksc.1040.0109

Grant, A. M. (2007). Relational job design and the motivation to make a prosocial difference. Academy of Management Review, 32, 393-417. doi:10.5465/AMR.2007.24351328

Grant, A. M., \& Berry, J. (2011). The necessity of others is the mother of invention: Intrinsic and prosocial motivations, perspective-taking, and creativity. Academy of Management Journal, 54, 73-96. doi:10.5465/ AMJ.2011.59215085
Higgins, E. T. (1987). Self-discrepancy: A theory relating self and affect. Psychological Review, 94, 319-340. doi:10.1037/0033-295X.94.3.319

Higgins, E. T. (1997). Beyond pleasure and pain. American Psychologist, 52, 1280-1300. doi:10.1037/0003-066X.52.12.1280

Higgins, E. T. (2000). Making a good decision: Value from fit. American Psychologist, 55, 1217-1230. doi:10.1037/0003-066X.55.11.1217

Higgins, E. T., Friedman, R. S., Harlow, R. E., Idson, L. C., Ayduk, O. N., \& Taylor, A. (2001). Achievement orientations from subjective histories of success: Promotion pride versus prevention pride. European Journal of Social Psychology, 31, 3-23. doi:10.1002/ejsp.27

Higgins, E. T., Roney, C. J., Crowe, E., \& Hymes, C. (1994). Ideal versus ought predilections for approach and avoidance distinct self-regulatory systems. Journal of Personality and Social Psychology, 66, 276-286. doi:10.1037/0022-3514.66.2.276

Higgins, E. T., Shah, J. Y., \& Friedman, R. (1997). Emotional responses to goal attainment: Strength of regulatory focus as moderator. Journal of Personality and Social Psychology, 72, 515-525. doi:10.1037/00223514.72.3.515

Hsee, C. K., \& Weber, E. U. (1997). A fundamental prediction error: Self-other discrepancies in risk preference. Journal of Experimental Psychology: General, 126, 45-53.

Hutchinson, J. M. C. (2005). Is more choice always desirable? Evidence and arguments from leks, food selection, and environmental enrichment Biological Reviews, 80, 73-92. doi:10.1017/S1464793104006554

Idson, L. C., Liberman, N., \& Higgins, E. T. (2000). Distinguishing gains from nonlosses and losses from nongains: A regulatory focus perspective on hedonic intensity. Journal of Experimental Social Psychology, 36, 252-274. doi:10.1006/jesp.1999.1402

Iyengar, S. S., Huberman, G., \& Jiang, W. (2004). How much choice is too much? Contributions to 401(k) retirement plans. In O. S. Mitchell \& S. Utkus (Eds.), Pension design and structure: New lessons from behavioral finance (pp. 83-95). Oxford, England: Oxford University Press.

Iyengar, S. S., \& Jiang, W. (2004). Choosing not to choose: The effect of more choices on retirement savings decisions. Unpublished manuscript.

Iyengar, S. S., \& Lepper, M. R. (2000). When choice is demotivating: Can one desire too much of a good thing? Journal of Personality and Social Psychology, 79, 995-1006. doi:10.1037/0022-3514.79.6.995

Iyengar, S. S., Wells, R. E., \& Schwartz, B. (2006). Doing better but feeling worse: Looking for the "best" job undermines satisfaction. Psychological Science, 17, 143-150. doi:10.1111/j.1467-9280.2006 .01677.x

Jonas, E., \& Frey, D. (2003). Information search and presentation in advisor-client interactions. Organizational Behavior and Human Decision Processes, 91, 154-168. doi:10.1016/S0749-5978(03)00059-1

Jonas, E., Schulz-Hardt, S., \& Frey, D. (2005). Giving advice or making decisions in someone else's place: The influence of impression, defense, and accuracy motivation on the search for new information. Personality and Social Psychology Bulletin, 31, 977-990. doi:10.1177/ 0146167204274095

Kahn, B. E., \& Wansink, B. (2004). The influence of assortment structure on perceived variety and consumption quantities. Journal of Consumer Research, 30, 519-533. doi:10.1086/380286

Koelemeijer, K., \& Oppewal, H. (1999). Assessing the effects of assortment and ambience: A choice experimental approach. Journal of Retailing, 75, 319-345. doi:10.1016/S0022-4359(99)00011-1

Kray, L. J. (2000). Contingent weighting in self-other decision making. Organizational Behavior and Human Decision Processes, 83, 82-106. doi:10.1006/obhd.2000.2903

Kühnen, U., \& Oyserman, D. (2002). Thinking about the self influences thinking in general: Cognitive consequences of salient self-concept Journal of Experimental Social Psychology, 38, 492-499. doi:10.1016/ S0022-1031(02)00011-2

Laran, J. (2010). Goal management in sequential choices: Consumer 
choices for others are more indulgent than personal choices. Journal of Consumer Research, 37, 304-314. doi:10.1086/652193

Larsen, R. J. (1987). The stability of mood variability: A spectral analytic approach to daily mood assessments. Journal of Personality and Social Psychology, 52, 1195-1204. doi:10.1037/0022-3514.52.6.1195

Lee, A. Y., Aaker, J. L., \& Gardner, W. L. (2000). The pleasures and pains of distinct self-construals: The role of interdependence in regulatory focus. Journal of Personality and Social Psychology, 78, 1122-1134. doi:10.1037/0022-3514.78.6.1122

Liberman, N., Trope, Y., \& Stephan, E. (2007). Psychological distance. In A. W. Kruglanski \& E. T. Higgins (Eds.), Social psychology: Handbook of basic principles (Vol. 2, pp. 353-381). New York, NY: Guilford Press.

Lockwood, P., Jordan, C. H., \& Kunda, Z. (2002). Motivation by positive or negative role models: Regulatory focus determines who will best inspire us. Journal of Personality and Social Psychology, 83, 854-864. doi:10.1037/0022-3514.83.4.854

McCauley, C., Kogan, N., \& Teger, A. (1971). Order effects in answering risk dilemmas for self and others. Journal of Personality and Social Psychology, 20, 423-424. doi:10.1037/h0031938

Mick, D. G., Broniarczyk, S. M., \& Haidt, J. (2004). Choose, choose, choose, choose, choose, choose, choose: Emerging and prospective research on the deleterious effects of living in consumer hyperchoice. Journal of Business Ethics, 52, 207-211. doi:10.1023/B:BUSI $.0000035906 .74034 . \mathrm{d} 4$

Mogilner, C., Aaker, J. L., \& Pennington, G. (2008). Time will tell: The distant appeal of promotion and imminent appeal of prevention. Journal of Consumer Research, 34, 670-681. doi:10.1086/521901

Mogilner, C., Rudnick, T., \& Iyengar, S. S. (2008). The mere categorization effect: How the presence of categories increases choosers' perceptions of assortment variety and outcome satisfaction. Journal of Consumer Research, 35, 202-215. doi:10.1086/588698

Payne, J. W. (1976). Task complexity and contingent processing in decision making: An information search and protocol analysis. Organizational Behavior and Human Performance, 16, 366-387. doi:10.1016/ 0030-5073(76)90022-2

Pennington, G., \& Roese, N. (2003). Regulatory focus and temporal distance. Journal of Experimental Social Psychology, 39, 563-576. doi:10.1016/S0022-1031(03)00058-1

Polman, E. (2010). Information distortion in self-other decision making. Journal of Experimental Social Psychology, 46, 432-435. doi:10.1016/ j.jesp.2009.11.003

Polman, E., \& Emich, K. J. (2011). Decisions for others are more creative than decisions for the self. Personality and Social Psychology Bulletin, 37, 492-501. doi:10.1177/0146167211398362

Preacher, K. J., \& Hayes, A. F. (2004). SPSS and SAS procedures for estimating indirect effects in simple mediation models. Behavior Research Methods, Instruments \& Computers, 36, 717-731. doi:10.3758/ BF03206553

Redelmeier, D. A., \& Tversky, A. (1990). The discrepancy between medical decisions for individual patients and for groups. New England Journal of Medicine, 332, 1162-1164. doi:10.1056/NEJM199004193221620

Reibstein, D. J., Youngblood, S. A., \& Fromkin, H. L. (1975). Number of choices and perceived decision freedom as a determinant of satisfaction and consumer behavior. Journal of Applied Psychology, 60, 434-437. doi: $10.1037 / \mathrm{h} 0076906$

Reutskaja, E., \& Hogarth, R. M. (2009). Satisfaction in choice as a function of the number of alternatives: When "goods satiate." Psychology and Marketing, 26, 197-203. doi:10.1002/mar.20268

Scheibehenne, B., Greifeneder, R., \& Todd, P. M. (2009). What moderates the too-much-choice effect? Psychology and Marketing, 26, 229-253. doi:10.1002/mar.20271

Scheibehenne, B., Greifeneder, R., \& Todd, P. M. (2010). Can there ever be too many options? A meta-analytic review of choice overload. Journal of Consumer Research, 37, 409-425. doi:10.1086/651235

Schubert, T. W., \& Otten, S. (2002). Overlap of self, ingroup, and outgroup: Pictorial measures of self-categorization. Self and Identity, 1 , 353-376. doi:10.1080/152988602760328012

Schwartz, B. (2000). Self-determination: The tyranny of freedom. American Psychologist, 55, 79-88. doi:10.1037/0003-066X.55.1.79

Schwartz, B. (2004). The paradox of choice: Why more is less. New York, NY: Ecco.

Sela, A., Berger, J., \& Liu, W. (2009). Variety, vice, and virtue: How assortment size influences option choice. Journal of Consumer Research, 35, 941-951. doi:10.1086/593692

Semin, G. R., Higgins, T., de Montes, L. G., Estourget, Y., \& Valencia, J. F. (2005). Linguistic signatures of regulatory focus: How abstraction fits promotion more than prevention. Journal of Personality and Social Psychology, 89, 36-45. doi:10.1037/0022-3514.89.1.36

Shah, A. M., \& Wolford, G. (2007). Buying behavior as a function of parametric variation of number of choices. Psychological Science, 18, 369-370. doi:10.1111/j.1467-9280.2007.01906.x

Spencer, S. J., Zanna, M. P., \& Fong, G. T. (2005). Establishing a causa chain: Why experiments are often more effective than mediational analyses in examining psychological processes. Journal of Personality and Social Psychology, 89, 845-851. doi:10.1037/0022-3514.89.6.845

Stone, E. R., Yates, A. J., \& Caruthers, A. S. (2002). Risk taking in decision making for others versus the self. Journal of Applied Social Psychology, 32, 1797-1824. doi:10.1111/j.1559-1816.2002.tb00260.x

Teger, A. I., \& Kogan, N. (1975). Decision-making for others under reciprocal and non-reciprocal conditions. British Journal of Social and Clinical Psychology, 14, 215-222. doi:10.1111/j.2044-8260.1975 .tb00174.x

Tordesillas, R., \& Chaiken, S. (1999). Thinking too much? Personality and Social Psychology Bulletin, 25, 623-629.

Triandis, H. C. (2001). Individualism-collectivism and personality. Journal of Personality, 69, 907-924. doi:10.1111/1467-6494.696169

Trope, Y., Liberman, N., \& Wakslak, C. (2007). Construal levels and psychological distance: Effects on representation, prediction, evaluation, and behavior. Journal of Consumer Psychology, 17, 83-95. doi:10.1016/ S1057-7408(07)70013-X

Turner, J., Oakes, P., Haslam, S. A., \& McGarty, C. (1994). Self and collective: Cognition and social context. Personality and Social Psychology Bulletin, 20, 454-463. doi:10.1177/0146167294205002

van Stekelenburg, J. (2006). Promoting or preventing social change: Instrumentality, identity, ideology and groups-based anger as motives of protest participation (Unpublished doctoral dissertation). Vrije Universiteit, Amsterdam, the Netherlands.

Wallach, M. A., Kogan, N., \& Bem, D. J. (1964). Diffusion of responsibility and level of risk taking in groups. Journal of Abnormal and Social Psychology, 68, 263-274. doi:10.1037/h0042190

Wilson, T. D., Lisle, D., Schooler, J. W., Hodges, S. D., Klaaren, K. J., \& LaFleur, S. J. (1993). Introspecting about reasons can reduce post-choice satisfaction. Personality and Social Psychology Bulletin, 19, 331-339. doi:10.1177/0146167293193010

Wilson, T. D., \& Schooler, J. W. (1991). Thinking too much: Introspection can reduce the quality of preferences and decisions. Journal of Personality and Social Psychology, 60, 181-192. doi:10.1037/00223514.60.2.181

Wray, L. D., \& Stone, E. R. (2005). The role of self-esteem and anxiety in decision making for self versus others in relationships. Journal of Behavioral Decision Making, 18, 125-144. doi:10.1002/bdm.490

Yates, F. J. (1990). Judgment and decision making. Englewood Cliffs, NJ: Prentice Hall.

Zaleska, M., \& Kogan, N. (1971). Level of risk selected by individuals and groups when deciding for self and for others. Sociometry, 34, 198-213. doi: $10.2307 / 2786410$ 
Zeelenberg, M. (1999). Anticipated regret, expected feedback and behavioral decision-making. Journal of Behavioral Decision Making, 12, 93-106. doi:10.1002/(SICI)1099-0771(199906)12:2<93::AIDBDM311>3.0.CO;2-S

Zikmund-Fisher, B. J., Sarr, B., Fagerlin, A., \& Ubel, P. A. (2006). A matter of perspective: Choosing for others differs from choosing for yourself in making treatment decisions. Journal of General Internal Medicine, 21, 618-622. doi:10.1111/j.1525-1497.2006.00410.x

Received September 17, 2010

Revision received December 14, 2011

Accepted December 15, 2011

\section{Members of Underrepresented Groups: Reviewers for Journal Manuscripts Wanted}

If you are interested in reviewing manuscripts for APA journals, the APA Publications and Communications Board would like to invite your participation. Manuscript reviewers are vital to the publications process. As a reviewer, you would gain valuable experience in publishing. The P\&C Board is particularly interested in encouraging members of underrepresented groups to participate more in this process.

If you are interested in reviewing manuscripts, please write APA Journals at Reviewers@apa.org. Please note the following important points:

- To be selected as a reviewer, you must have published articles in peer-reviewed journals. The experience of publishing provides a reviewer with the basis for preparing a thorough, objective review.

- To be selected, it is critical to be a regular reader of the five to six empirical journals that are most central to the area or journal for which you would like to review. Current knowledge of recently published research provides a reviewer with the knowledge base to evaluate a new submission within the context of existing research.

- To select the appropriate reviewers for each manuscript, the editor needs detailed information. Please include with your letter your vita. In the letter, please identify which APA journal(s) you are interested in, and describe your area of expertise. Be as specific as possible. For example, "social psychology" is not sufficient-you would need to specify "social cognition" or "attitude change" as well.

- Reviewing a manuscript takes time (1-4 hours per manuscript reviewed). If you are selected to review a manuscript, be prepared to invest the necessary time to evaluate the manuscript thoroughly. 